\title{
Journal of Korean Academy of Psychiatric and Mental Health Nursing Accepted for Inclusion in SCOPUS
}

\author{
Kim, Hee Sook ${ }^{1} \cdot$ Kim, Young Joo ${ }^{2}$ \\ ${ }^{1}$ 1Editor-In-Chief, Journal of Korean Academy of Psychiatric and Mental Health Nursing, \\ College of Nursing · Research Institute of Nursing Science, Kyungpook National University, Daegu \\ ${ }^{2}$ Temporary Managing Editor, Journal of Korean Academy of Psychiatric and Mental Health Nursing, Daegu, Korea
}

\section{INTRODUCTION}

On the morning of May 16, 2021, the editor-in-chief and the temporary managing editor of Journal of Korean Academy of Psychiatric and Mental Health Nursing (KPMNH) received an email from the SCOPUS Title Evaluation Team stated that "The title mentioned above has been evaluated for inclusion in Scopus by the Content Selection \& Advisory Board (CSAB). The review of this title is now complete and the CSAB has advised that the title will be accepted for inclusion in SCOPUS."

Since 2014, KPMHN has been trying to become an international journal. We are glad to share this announcement with readers, authors, and reviewers of KPMHN. Without their help, it would not have been possible to be accepted by the SCOPUS CSAB. It is worthwhile to present chronological details of the journal's application process to SCOPUS [1]. This information will help editors of society and nonprofit organization journals understand the process.

\section{Achieving SCOPUS Standards}

To become an academic journal that meets international standards, the editorial committee of KPMHN continues to make efforts to improve the quality of the journal. After applying for Scopus registration in 2014, we made efforts to reinforce the lack of professional academic activities of editorial members, the main reason for the "failure" in November 2015.

We joined the Korean Association of Medical Journal
Editors (KAMJE) which promotes the quality of medical journals published in Korea through an exchange of information among its various journals like the Korean Medical Journal Information (KAMJI). We also included more overseas researchers in international health as editorial members to improve the professionalism, specificity, and internationalization of the journal. Peer review helps validate manuscripts submitted for publication in scientific journals [2]. After making these adjustments, we reapplied for SCOPUS registration in October of 2020.

\section{Creating Easy Access for a Global Audience}

In September 2017, "The Journal of Korean Psychiatric and Mental Health Nursing Academy" was changed to "Journal of Korean Academy of Psychological and Mental Health Nursing" to facilitate the search and citation of papers by foreign researchers.

In addition, the English online contribution system was established in 2017 to encourage contribution of overseas papers. The English homepage is being steadily upgraded [3]. It provides full journal contents online [3]. This journal introduces and appropriately utilizes an online thesis contribution and examination management system (https:// mhn.medicallove.com/) in accordance with thesis contribution regulations and thesis review regulations on the contribution and examination system of contribution papers. The online submission system located at the bottom left of the website of the Korean Psychiatric Nursing Association allows users to log in immediately, making it relatively easy to access and utilize.

\footnotetext{
Corresponding author: Kim, Hee Sook https://orcid.org/0000-0002-8669-0166

Editor-In-Chief, Journal of Korean Academy of Psychiatric and Mental Health Nursing, College of Nursing, Kyungpook National University, 680 Gukchaebosang-ro, Jung-gu, Daegu 41944, Korea.

Tel: +82-53-420-4927, Fax: +82-53-422-4926, E-mail: hskim4114@nate.com
}

Received: Sep 1, 2021 | Accepted: Sep 13, 2021

This is an open access article distributed under the terms of the Creative Commons Attribution Non-Commercial License (http://creativecommons.org/licenses/ by-nc/3.0), which permits unrestricted non-commercial use, distribution, and reproduction in any medium, provided the original work is properly cited. 
The online submission system is designed for authors, editorial members, publishing chairmen, and managing editors. It is accessible only to those who have obtained the relevant authority. Accordingly, the correspondence author can make frequent contributions using the online thesis contribution system to receive the manuscript. When making a contribution, he/she shall write down the matters to be inspected.

The process for applying and obtaining approval of SCOPUS registration in chronological order is shown below:

- On September 28, 2014: The first application to SCOPUS was submitted and rejected. Reasons for rejection were as follows: "Citedness is below expectations. There is no international diversity among authors. Only one issue is published per year. Also, author instructions need to be described more in detail."

- The second application to SCOPUS was completed on October 7, 2020 by submitting a reply to the feedback received when applying for SCOPUS in 2014.

- An update on the progress came in April of 2021, when we received notice saying results would be released in two weeks.

- Confirmation of the process of application for registration was given in May, 2021.

- Received acceptance letter on May 16, 2021, stating we completed the list of requests given by SCOPUS and some recommendations for improvements in the future.

In total, it took about eight years from application to acceptance by the SCOPUS CSAB.

\section{Final Thoughts}

For any journal, the breadth of countries represented by authors can provide evidence of the international scope of that journal. According to the previously mentioned article, the breadth of countries of authors provides evidence of the internationality of a journal [4]. Therefore, a variety of countries in the KPMHN's authorship provides proof of its internationality.

We understand that citedness reflects international ranking and quality of a journal. KPMHN is consistently published four times a year. As of 2020, KPMHN's four-year impact factor (KCI IF) was 1.37 and its KCI centrality index (KJR) was 1.67. It was ranked 7th out of 27 journals in nursing. Its English homepage is being steadily upgraded which secures diversity in geographical distribution of authors.

The KPMHN will be reborn as a journal accessible to users with the latest and best interdisciplinary contents suitable for internationally recognized levels of expertise of SCOPUS. We will focus and cultivate the expertise of editors internationally and maintain its content quality through continuous re-evaluation by SCOPUS.

\section{CONFLICTS OF INTEREST}

The authors declared no conflicts of interest.

\section{ORCID}

Kim, Hee Sook

Kim, Young Joo

https://orcid.org/0000-0002-8669-0166 https://orcid.org/0000-0001-6830-1940

\section{REFERENCES}

1. Content Policy and Selection - Content - Scopus - Solutions | Elsevier [cited 2021 Sep 15]. Available from:

https://www.elsevier.com/solutions/scopus/how-scopusworks/content/content-policy-and-selection\#cps

2. Kähler O. Combining peer review and metrics to assess journals for inclusion in Scopus. Learned Publishing. 2010;23(4):336-346. https://kpmhn.or.kr/new/eng/main/main.php [cited 2021 Sep 15]

3. https://kpmhn.or.kr/new/eng/main/main.php [cited 2021 Sep 15]

4. Huh S. Journal of Educational Evaluation for Health Professions will be accepted for inclusion in Scopus. Journal of Educational Evaluation for Health Professions; 2019. 16. 